\title{
Design, Analysis and Optimization of Drag Chain Conveyor System for Coal Application
}

\author{
Unmesh Nandkishor Gatade \\ Dept. of Mechanical Engineering, \\ SSGMCE, Shegaon.
}

\author{
Vaibhav Punjaram Makode \\ Dept. of Mechanical Engineering, \\ SSGMCE, Shegaon.
}

\author{
Gaurav Vishvanath Thote \\ Dept. of Mechanical Engineering, \\ SSGMCE, Shegaon. \\ Sumit Harishchandra Ingole \\ Dept. of Mechanical Engineering, \\ SSGMCE, Shegaon.
}

\author{
Vikaskumar Omnarayan Yadav \\ Dept. of Mechanical Engineering, \\ SSGMCE, Shegaon. \\ Yogesh Ashok Wanve \\ Dept. of Mechanical Engineering, \\ SSGMCE, Shegaon.
}

\begin{abstract}
Drag chain conveyors are the most effective way to move or elevate bulk material and transfer it from point to point. The design, layout configurations, service duty rating, size of the casing and flight assembly are all components that make a significant difference on the quality, durability and longevity of any given drag conveyor. This report is an attempt to put in words the experience of our exposure to Design and Analysis of Drag Chain Conveyor System. The aim and objective was to optimize existing Drag Chain Conveyor System. The design involves working on heavy structure, high scale vibration, and overweight bottom chassis. Procedure of selecting material played an important role in achieving the objectives. All the procedures and operations are done keeping in mind the dimensional restrictions along with economic views. We tried to give the direction according to developing industrial sector in India and provide best alternatives. Finite Element Analysis is also done for better understanding to optimize the load or weight. Total objective is achieved by tool SOLIDWORKS 2018.
\end{abstract}

Keywords-Drag Chain Conveyor; Design; Analysis; Vibrations; Material.

\section{INTRODUCTION}

A conveyor consisting of wooden or steel plates attached to endless chains and running in a trough through which the material is dragged. Drag chain conveyors are commonly utilized to transport coal, wood, refuse, or scrubber sludge in power plants, pulp and paper mills, and waste-toenergy facilities.

Drag conveyors, variously called drag chain conveyors, scraper chain conveyors and en-masse conveyors, are used in bulk material handling to move solid material along a trough. They are used for moving materials such as cement clinker, ash, and sawdust in the mining and chemical industries, municipal solid waste incinerators, and the production of pellet fuel.

The difference between drag conveyors, scraper conveyors, and flight conveyors largely depends on whether the chain links have obvious flights or paddles attached. In a drag conveyor, the chain moves the material directly, while a flight conveyor uses a series of wood, metal, or plastic flights attached to the chain at regular intervals, which push the material along the trough.

The standard drag conveyor, or simply the drag chain conveyor uses two endless chains with evenly spaced paddles between them, which drag along the bottom of a trough to transport material. The amount of bulk moved by each paddle is dictated by its surface area, as well as the chain speed, and they are replaceable once they wear down. The chain speed is typically slow which decreases energy consumption, and the whole assembly is easy to use, simple, and cost-effective. Certain models can run at up to $50 \mathrm{ft} / \mathrm{min}$ with a capacity of 10 cubic feet per minute at a length up to 400 feet per drive. They are ideal for non-sanitary, non-abrasive products such as grain, pebbles, and more, and are often used as feeders for other machines. Their major disadvantages are their propensity to wear down, as materials interact directly with the chain and can cause issues. Also, the chains will unevenly stretch over time, requiring consistent maintenance to ensure proper alignment. Drag chain conveyors can be configured to meet your unique specifications and keep your capital investment costs as well as operating and maintenance expenses to a minimum.

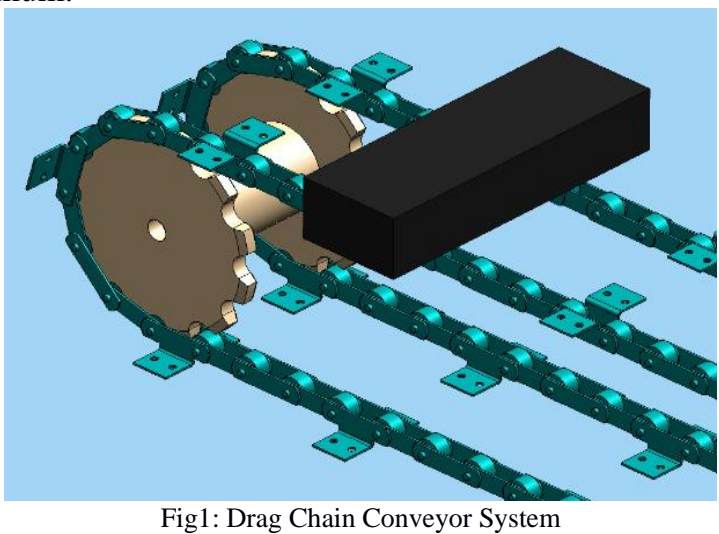

II. METHODOLOGY

A Specific methodology has to be adopted for the completion of any project and over project is no exception to that. The methodology consists of number of steps which are as follows.

\section{A. UNDERSTANDING CUSTOMER NEEDS}

As per the requirements, we need to reduce the fatigue cycle damage from $13 \%$ to $3 \%$ reduce the weight of the shaft assembly, reduce the vibrations in chassis and reduce its weight. To do this we first study the existing design and chassis by analysis of the parts.

\section{B. G A LAYOUT}

The general arrangement drawings present the overall design of the object. Depending on the complexity of the design it is likely to require a number of different projections such as 
planes, sections and elevations, and may be spread across drawing of different compositions. The G A Layout is generally supplied by the client and design is made accordingly. It works as a basic blueprint of the project.

\section{MATERIAL SELECTION}

There are three methods for material selection

1) Cost per unit property method.

2) Weighted property method.

3) Digital Logic Method.

Here we are using Digital Logic Method

i For Strength, Toughness, etc.

Scaled Property $=($ Numerical Value of property $\mathrm{x}$ 100)/Max.Value in the list

ii For Cost, density corrosion, etc.

Scaled Property $=($ Min. Value in the list $\mathrm{x}$ 100)/Numerical Value of property

iii Material Performance Index is given as

$$
\text { Material performance index, } \gamma=\sum_{i=1}^{n} B_{i} \alpha_{i}
$$

iv Figure of merit (FOM) for the material can then be defined as : $\mathrm{C}$ is the total cost of the material per unit weight (stock, processing, finishing, etc.) it is based from type of loading $\rho$ is the density of the material

$$
M=\frac{\gamma}{C \rho}
$$

$v$ Refined FOM : $\mathrm{C}^{\prime}$ is relative cost of material and is defined as the ratio of the price per unit mass of the material and low carbon steel

$$
\text { As taking above terminologies in } \quad M=\frac{\gamma}{C^{\prime}} \text { consideration let }
$$
us understand how we implemented this process for our design. Step 1- Screening: It include function, objective, variable, constraint

Step 2 - Property Selection (Appropriate property should be taken under consideration according to screening)

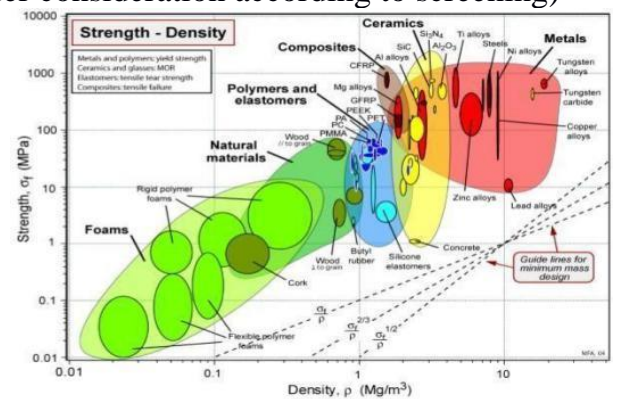

Fig. 1. Property Chart

\section{Step3 - Candidate Material Selected}

1) 4340 Steel

2) Aluminum Alloy (2024-T6)

3) Titanium Alloy (Ti-6Al-4V)

Applying Digital Logic Method for above materials and the one with highest Profile Index and Material Evaluation Factor is selected.

Result: The one with highest material evaluation factor is considered as final material for the product. In our case of Drag Chain Conveyor its $\mathbf{4 3 4 0}$ Steel.

\section{Modelling Parts AND ASSEmbling}

We create the 3D models of the parts in the SOLIDWORKS software, the 3D model give a correct view of the part. It is much easier to change the parameters of the project while it is in design phase as it helps to save the losses which can be caused after the final construction. As per the requirements and by doing the calculations we model the parts like base frame, shaft, drive mechanism, belt and roller. And finally after the completion of the parts we did the assembly of the Drag Chain Conveyor.

\section{E. PERFORMANCE ANALYSIS}

After the completion of the parts we did the analysis on them to analyze the stress distribution, deformation and various parameter so as to test if the parts fulfill the customer requirements. Static and Dynamic analysis on shaft are done as it is an important component in transmitting the power and torque. Analysis on base frame, drive shaft and idler roller are also done. Drive shafts are subject to torsion and stresses, that's why they need to be strong enough to bear the stress while avoiding additional weight as this increases the material consumed increasing the cost and also increase the inertia consuming more power.

\section{MODELLING AND ANALYSIS}

\section{A. Modelling Parts and ASSEmblies}

Modelling is defined as the complete representation of an object or a system with the graphical and non-graphical information. It is also known as geometric modelling. It generates the mathematical description of the geometry and non-geometry of an object or a system in the computer database and the image of an object or system on the graphic screen. With the use of modelling the designer constructs the graphical image of an object on the computer screen.

\section{B. FEA ANALYSIS}

Finite Element Analysis (FEA) is a method of analyzing how a part or assembly will perform over its lifetime. FEA can be used to optimize the performance of a new product, verify an existing product, or modify a product for a new condition. By including FEA as part of our product development process, we can simulate the effects that real world extremes will have on our design before we have created a physical prototype. This virtual prototyping saves our substantial time and cost by minimizing the number of physical prototypes required.

\section{Advantage of FEA}

1. According to strength of materials the stress in a body is assumed to be uniform but in reality it is distributed. This can be shown by finite element method.

2. It can solve models having complex geometry and show the stress concentrated area.

3. It helps the design engineer to optimize the model before fabrication. Hence saving time and money.

4. Multi-purpose analysis is also possible due to FEA.

Below are important components analysis which helped to reach the objective 
- Shaft Analysis:

For the analysis of shaft we considered following input data which is as follow:

1. Force Applied: $-12000 \mathrm{~N}$.

2. Faces to be fixed:- 2 faces (i.e. which is going to be attached with the key)

3. Shaft material:- AISI 4340 Steel, normalized

Steps in Analysis

1. Applying Material before starting with analysis we have to apply first of all material to the component. We have selected AISI 4340 Steel, normalized as material for Conveyor system.

2. Applying Fixture we can used various commands like fixed support, roller support, hinged support, etc. to a face of component. We have fixed the back face 2 of shaft which is going to attached with the key

\section{Meshing}

Meshing is defined as the process of dividing the whole component into number of elements so that whenever the load is applied on the component it distributes the load uniformly called as meshing.

A component is analyzed in two ways. One is with Meshing and the other is without meshing.

a With Meshing: If the load is applied on the structure or a body and the body is considered to be meshed, then the load is distributed uniformly on the entire structure.

b After Meshing, the entire structure is divided into number of elements and each element having its own stiffness while loading.

c Adding all those elements stiffness, we can get the Global Stiffness Matrix with which we can calculate the stress developed in the structure etc.

d If the Von miss stress is less than yield stress of the material, then the product analyzed is safe, else it is of failure type.

e Without Meshing: If we are applying the load on the body which is not meshed, then the load distribution is not uniform and we may get the irregular or faulty results.

\section{Stress Analysis:}

From stress analysis of a component we can study and see the stress distribution over the component surface due to the forces acting on it which is not possible to find theoretically.

\section{Displacement Analysis:}

From displacement analysis we can study the deformation of component due to force acting on it.

\section{Factor of Safety:}

From this analysis we can study the ability of a system's structural capacity to viable beyond its expected or actual loads.

\section{- Intermediate Casing Analysis:}

For analysis of Intermediate Casing we have considered following input data which is as follow:

1. Force Applied :- $2146 \mathrm{~N}$

2. Casing Material :- AISI 1040
Steps in Analysis

1. Applying Material before starting with analysis we have to apply first of all material to the component. We have selected AISI 4340 Steel, normalized as material for Conveyor system.

2. Applying Fixture we can used various commands like fixed support, roller support, hinged support, etc. to a face of component.

3. Meshing :

The meshing distributes the load uniformly over structural member.

4. Stress Analysis:

From stress analysis of a component we can study and see the stress distribution over the component surface due to the forces acting on it which is not possible to find theoretically.

5. Displacement Analysis:

From displacement analysis we can study the deformation of component due to force acting on it.

\section{Factor of Safety:}

From this analysis we can study the ability of a system's structural capacity to viable beyond its expected or actual loads.

\section{RESULT AND DISCUSSION}

The required modifications achieved in this project are,

a. The fatigue cycle damage is reduced from $13 \%$ to $3 \%$ followed by fatigue analysis on shaft.

b. As drive shaft assembly was over weighted initially we successfully reduced the weight by FRP material and optimized weight is achieved.

c. Fulfilling problem statement, Increases the capacity of coal at outlet.

d. Vibration in bottom chassis of the belt conveyor is reduced up-to 45 Hertz followed by vibration analysis

e. As chassis was overweight initially we reduced it upto $253 \mathrm{~kg}$ by weight optimization thus, we successfully achieved the objectives of our project.

\section{CONCLUSION}

In this paper we addressed the optimization problem of Drag Chain Conveyor System which arises due to over weight of support chassis, less coal outlet capacity, vibrations in bottom chassis. The objective of this work was to modify the present design of Drag Chain Conveyor System with CAD application (SOLIDWORKS 2018)

The proposed design allows optimization of Drag Chain Conveyor System which results in, increase in coal outlet capacity, reduction in weight of support chassis, increase in fatigue cycles of shaft, reduction in vibrations in bottom chassis by the proper material selection, analysis and design calculations of Drag Chain Conveyor.

\section{ACKNOWLEDGEMENT}

We would like to express our deepest appreciation to all those who provided us the possibility to complete this report. It would not have been possible without the help and guidance of various people throughout the making of this work. A special gratitude we give to our guide, Prof. N. B. Borkar, whose contribution in stimulating suggestions and 
encouragement, helped us to coordinate especially in writing this paper. We are highly indebted to him for his guidance and constant supervision as well as for providing necessary information from time to time. We owe our deep gratitude to Dr S. P. Trikal, HOD of Dept. of Mechanical Engineering, and Dr. S. B. Somani, Principal, Shri Sant Gajanan Maharaj College of Engineering, Shegaon for their encouragement and more over for their timely support and guidance. We express our sincere esteems to our colleagues who helped willingly in completion of this system.

\section{REFERENCES}

[1] F.L.D. Cloete and P. Kirsten, "Drag Chain Conveyor based on standard engineering components", CSIR Report CENG 118, April 1976

[2] Shinde S and Patil R B, "Design and Analysis of Roller Conveyor System for Weight Optimization and Material Saving",International Journal on Emerging Technologies - ISSN(0)-2249-3255, Vol-3 Issue-1,pp. 168-173, April 2012

[3] M.F. Ashby, "Material Selection in Machine Design",Cambridge University England., $2^{\text {nd }}$ edition. ISBN 0750643579

[4] R.S. Khrumi and J.k. Gupta, "Machine Design", Eurasia publishing house pvt. Ltd., 14th edition. pp. 345-420.

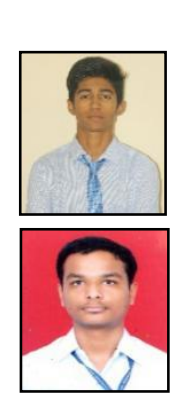

\section{AUTHORS PROFILE}

Unmesh Nandkishor Gatade

Bachelor of Mechanical Engineering, (2016-2020) Shri Sant Gajanan Maharaj College of Engineering, Shegaon (M.H.)

\section{Gaurav Vishvanath Thote}

Bachelor of Mechanical Engineering, (2017-2020) Shri Sant Gajanan Maharaj College of Engineering, Shegaon (M.H.)

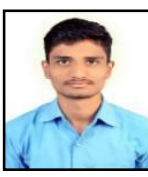

\section{Vaibhav Punjaram Makode}

Bachelor of Mechanical Engineering, (2016-2020) Shri Sant Gajanan Maharaj College of Engineering, Shegaon (M.H.)

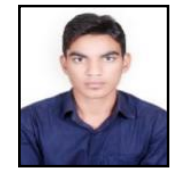

\section{Vikaskumar Omnarayan Yadav}

Bachelor of Mechanical Engineering, (2016-2020) Shri Sant Gajanan Maharaj College of Engineering, Shegaon (M.H.)

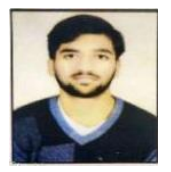

\section{Sumit Harishchandra Ingole}

Bachelor of Mechanical Engineering, (2017-2020) Shri Sant Gajanan Maharaj College of Engineering, Shegaon (M.H.)

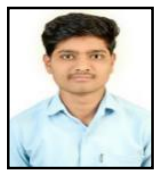

\section{Yogesh Ashok Wanve}

Bachelor of Mechanical Engineering, (2016-2020) Shri Sant Gajanan Maharaj College of Engineering, Shegaon (M.H.) 